\title{
Illusory Nature of Pricing of Illiquidity Risk: The Test Case of
}

\section{Australian Stock Market}

\author{
Hilal Anwar Butt* $\quad$ Ihsan Ullah Badshah ${ }^{\dagger} \quad$ Muhammad Tahir Suleman ${ }^{\ddagger}$
}

\begin{abstract}
Positive illiquidity premium is documented to be linked with the illiquidity effect across global markets. This evidence is generally suggested through some asset pricing model, such as Acharya and Pedersen (2005) or others. Our study shows that the success of any such model in terms of magnitude of predicted risk premium is linked with measure of illiquidity used in the study. The main implication of this evidence is that the variety of illiquidity related risk premiums can be reported for the same market, or for the number of markets. To elaborate this point, the test case of Australian stock market is taken and likely strategy to determine the maximum illiquidity premium is proposed.
\end{abstract}

Keywords: Asset pricing, Australian stock market, illiquidity premium, illiquidity measures.

\section{Introduction}

The impact of illiquidity on the stock prices has extensively been studied for numerous markets internationally (Amihud, 2002; Fong, Holden, \& Trzcinka, 2017; Raza \& Karim, 2016). It is reported that illiquidity both as a stock related characteristic (illiquidity level) and as systematic risk (illiquidity risk) is priced. These results are important, however the chink in the armor for illiquidity related literature is that there is no consensual definition of the illiquidity. Resultantly the choice of illiquidity measure for any study, among many proposed in literature (see (Roll, 1984; Lesmond, Ogden, \& Trzcinka, 1999; Amihud, 2002; Fong et al., 2017; Corwin \& Schultz, 2012) etc.) is arbitrary. Does this have any impact for the magnitude of reported illiquidity premium? Either reported as return dispersion between the most illiquid and liquid portfolios, or as a factor premium predicted by some asset pricing model for a market, or for a panel of global markets?

This inquisition has important application for risk analysis, such that what is an extent of illiquidity risk to which any an investment is exposed to, or what should be the magnitude of compensation of this risk in a shape of illiquidity premium. This study explores this question to find out, that unlike the league of other risk factors, like market, size and value and others, the illiquidity premium for the same sample of stock returns varies with the choice of one measure of illiquidity to another. Therefore, a plethora of differential evidence may emerge on the same market, which may help little to academics and practitioner alike.

\footnotetext{
* Department of Economics and Finance, Institute of Business Administration Karachi, Pakistan. E-mail: habutt@iba.edu.pk.

${ }^{\dagger}$ Department of Finance, Auckland University of Technology, Private Bag 92006, 1020 Auckland, New Zealand.

${ }^{\ddagger}$ School of Economics and Finance, Victoria University, Wellington, New Zealand.
} 
To fix the ideas, we present the different illiquidity premium evidence for the Australian market using two different measure of illiquidity and then suggest a possible strategy to determine the maximum illiquidity cap for a market, or a panel of global markets?

The remainder of this paper is organized as follows: Next sections discuss the empirical studies and liquidity adjusted CAPM model, data analysis, results and then conclusion.

\section{Literature Review}

The choice of Australian market is natural as it facilitates us to study two influential papers of (Lee, 2011; Amihud, Mendelson, Pedersen, et al., 2005) on this topic. Lee (2011) finds that there is no illiquidity premium (see, Table 3 in Lee (2011)) associated with local illiquidity risks for the panel of developed markets (including Australia) when estimated using Acharya and Pedersen (2005) model. The local illiquidity risk for each country is measured by average monthly shocks in zero returns, a measure of illiquidity proposed by Lesmond et al. (1999). As the premium is estimated for panel of countries with the possibility that there are some countries at margins. Therefore we estimate the illiquidity premium individually for Australian market using the same measure of illiquidity and model as of Lee (2011), although our test is less rigorous, that is, we have not included market, size and value factors to control for other risk factors. In spite of that, we find as in Lee (2011) that factor premium for Australian market is insignificant.

In the other study of Amihud, Hameed, Kang, and Zhang (2015) illiquidity is estimated as a response of per dollar traded volume upon absolute returns of any firm, a measure proposed in Amihud (2002) and referred as price impact. The illiquidity premium for Australian market associated with price impact is $19.31 \%$ on annual basis for equally weighted portfolios ${ }^{1}$. We also find similar illiquidity premium, as a return dispersion between the most illiquid and liquid portfolios for the Australian market for the time span of February, 1988 to June, 2014, using price impact measure. One possibility could be that illiquidity related risks designed in Acharya and Pedersen (2005) are not adequate enough to predict any illiquidity premium. However, such is not the case as once the procedure in Lee (2011) is repeated using price impact measure, the model based illiquidity factor premium associated with one illiquidity related beta is $18.05 \%$ on annual basis.

We conjecture that the different evidence of illiquidity premium for the same market and sample, by implying the same methodology, is in nutshell a test of the success of any illiquidity measure used in the analysis. For instance, the cross-sectional returns dispersion between the most illiquid (P-10) and liquid (P-1), portfolio is $7.33 \%$ on annual basis, when stocks are partitioned into deciles (ten portfolios) on the basis of previous month's zeroreturns. Whereas, the same return dispersion is $17.96 \%$ on annual basis for the price impact measure. Resultantly, the success of price impact in bringing the higher return spread also translated into success of Acharya and Pedersen (2005) LCAPM model based factor premium.

This variation in pricing of illiquidity owing to different measure of illiquidity is also reported in Lee (2011) for the US market. Surprisingly the impact of these findings on

\footnotetext{
${ }^{1}$ This result is available on the online appendix of the paper Amihud et al. (2015), (see Table 1)
} 
the magnitude of illiquidity premium for international stock markets is ignored. One of the potential implication is that the extent of illiquidity premium in Lee (2011) might be underestimated if along with Australian market there are other markets for which significant illiquidity risk cannot be established with zero-returns. Since there is significant presence of illiquidity premium through price impact measure therefore that contribution of premium of Australian market is missed out for the developed markets in Lee (2011).

Foregoing does not imply that price impact is the best measure of illiquidity, which is analyzed in Amihud et al. (2015) for 45 international stock markets. In one of the study by Butt and Virk (2015), the illiquidity premium associated with zero-returns is shown to be higher for Finland in comparison to price impact measure. To elaborate it further, we replicated the portfolios formation procedure and time span that is 1997-2011 of Amihud et al. (2015) and find that premium associated with zero-returns is $6.95 \%$ for Finland, whereas the same with price impact is $1.28 \%$ on annual basis ${ }^{2}$. So, in the context of Finland, the zero-returns as an illiquidity measure is more relevant than price impact measure. This again leads to a same conjecture that the magnitude of illiquidity premium for few markets among 45 in Amihud et al. (2015) could be higher than reported in that study.

Therefore this study suggests that, the set of all possible measures of illiquidity proposed in the literature should be used to first ascertain which measure gives the maximum return differential between the most illiquid and liquid portfolio. As the best proxy measure of illiquidity cannot be established on ex-ante basis for each market, despite that such is generally the practice in vogue for the literature on illiquidity pricing. On the other hand this paper demonstrate that the success of pricing of illiquidity risk is linked with the success of illiquidity measure in finding out the return spread. Our proposed strategy may results in selection of different measures of illiquidity for different countries instead of one. The potential benefit is that the maximum illiquidity premium across the international stock markets can be determined.

\section{Capital Asset Pricing Model Adjusted for Illiquidity Risk}

One of the general findings from the liquidity literature is that the illiquid stocks pay higher returns in comparison to liquid stocks. Alternatively it can be said that a zeroinvestment strategy of being short in liquid stocks and long in illiquid stocks yields positive returns. These positive returns are generally not explained by the capital asset pricing model (CAPM). One among many possible reasons is that the model assumes that liquidity risk does not exist. As a consequence, the market beta is generally lower for illiquid (and higher for liquid) stocks. To correct the CAPM for liquidity related risk, Acharya and Pedersen (2005) proposed an illiquidity based adjustment. If returns are seen in their net denomination (that is, gross returns in excess of illiquidity related cost), then CAPM (subject to additional assumptions) can be expressed as the illiquidity adjusted CAPM (LCAPM), in which returns are a function of stock's expected illiquidity and three additional illiquidity related betas (in addition to the market beta).

\footnotetext{
${ }^{2}$ Different set of sorting procedure were used and we find consistent higher premium associated with zero measure, these results can be furnished upon request.
} 
The detailed assumptions under which the LCAPM is derived are spelled out in Acharya and Pedersen (2005) and (Amihud et al., 2005). One can infer from these assumptions that the CAPM in frictionless economy of Sharpe (1964); Lintner (1965); Mossin (1966); Black (1972) translates into LCAPM in which frictions to trade do exist. That is, the investor's equilibrium gross returns on some stock and overall market returns $R_{m t}$ in the CAPM are feasible and optimal in their net returns denominations such as, $R_{i t}-C_{i t}$ and $R_{m t}-C_{m t}$ in the LCAPM under some reduced investment opportunity set for the investors, this reduced opportunity set is direct out-come of additional assumptions implied in Acharya and Pedersen (2005). In the foregoing net returns, $C_{i t}$ and $C_{m t}$ are the liquidation cost (cost of selling), of some stock and of overall market, respectively ${ }^{3}$. This simple relationship between gross returns and net returns means the CAPM can be expressed as

$$
E_{t}\left(R_{i, t+1}-C_{i, t+1}\right)=R_{f}+\lambda_{t} \frac{\operatorname{Cov}_{t}\left(R_{i, t+1}-C_{i, t+1}, R_{m, t+1}-C_{m, t+1}\right)}{\operatorname{Var}_{t}\left(R_{m, t+1}-C_{m, t+1}\right)}
$$

The above equation 1 adjusts the future expected returns for the stochastic effect of illiquidity for the information that is available at time $t$. The unconditional version for testing the illiquidity effect can be written as below, by assuming (as in Acharya and Pedersen (2005)) that the conditional covariance in equation (1) is constant:

$$
E\left(R_{i}-C_{i}\right)=E\left(C_{i}\right)+\lambda_{1} \beta_{i, m}+\lambda_{2} \beta_{i, L 1}-\lambda_{3} \beta_{i, L 2}-\lambda_{4} \beta_{i, L 3}
$$

The respective betas are,

$$
\begin{aligned}
& \beta_{i, m}=\operatorname{Cov}\left(R_{i, t}, R_{m, t}\right) / \operatorname{Var}\left(R_{m, t},-C_{m, t}\right), \\
& \beta_{i, L 1}=\operatorname{Cov}\left(C_{i, t}, C_{m, t}\right) / \operatorname{Var}\left(R_{m, t},-C_{m, t}\right), \\
& \beta_{i, L 2}=\operatorname{Cov}\left(R_{i, t}, C_{m, t}\right) / \operatorname{Var}\left(R_{m, t},-C_{m, t}\right), \\
& \beta_{i, L 3}=\operatorname{Cov}\left(C_{i, t}, R_{m, t}\right) / \operatorname{Var}\left(R_{m, t},-C_{m, t}\right) .
\end{aligned}
$$

The detailed interpretation of these betas is given in Acharya and Pedersen (2005). The market beta $\beta_{i, m}$ signifies the risk of stocks in conjunction with market returns. If the stock's return has higher covariance with market returns, then it shows the riskiness of that respective stock in terms of higher value of $\beta_{i, m}$. That is, if the market gives lower returns then such stock gives lower returns than market returns; therefore their higher returns on average is basically compensation for not being hedged against poor marketwide performance. Similarly, for other illiquidity related betas, the pricing implication is the same. For example, $\beta_{i, L 1}$ (the commonality in liquidity, first studied by Chordia, Roll, and Subrahmanyam (2002) signifies the covariance between idiosyncratic illiquidity of the

\footnotetext{
${ }^{3}$ As discussed in Bekaert, Harvey \& Lundblad (2007) the Acharya and Pedersen (2005) model is a transaction cost based model. However it can be applied to other illiquidity measures as well. Stocks which have higher illiquidity must have higher transaction costs, therefore there is a direct link between any illiquidity measure and transaction costs.
} 
stock and the market's illiquidity. If a stock becomes illiquid when the overall market is illiquid, then an investor requires the illiquidity premium for investing in such a stock, as it becomes hard to liquidate the position when stock market illiquidity is higher.

Similarly, $\beta_{i, L 2}$ which is the covariance between stock $i^{\prime} s$ return and overall market illiquidity is generally priced negatively. If market illiquidity increases and the return on a stock also increases and vice-versa, then such a stock provides a hedge against the illiquidity risk and should earn a lower return accordingly. Lastly, $\beta_{i, L 3}$ captures the covariance between overall market returns and stock illiquidity. When stock market returns are depressed and illiquidity of a stock also reduces (and vice-versa), then such stocks allow an investor to easily liquidate his/her position when market returns are low. That is such stocks are hedged against the worst economic conditions.

\section{Data, Illiquidity Measure and Portfolios Formation}

\section{Data}

We obtain data from DataStream for the period of February, 1988 to June, 2014 (19882014, hereafter) for the Australian equity market. The initial sample consists of more than 3500 firms which include both active and dead firms in the sample. We include dead firms in order to avoid survivorship bias. To create a trustworthy sample, we first filter the non-common equity stocks from the sample. We follow (Griffin, Kelly, \& Nardari, 2010; Lee, 2011; Ince \& Porter, 2006) cleaning procedures. After this, we end up with 2822 firms. The number of firms is quite similar to the one reported in Amihud et al. (2015) for the Australian stock Market ${ }^{4}$. Following Griffin et al. (2010); Ince and Porter (2006), to avoid extreme observations prevalent in the DataStream, the daily returns are considered to be missing if any daily return $r_{t-1}>100 \%$ or $r_{t}>100 \%$ and $\left(1+r_{t}\right) *\left(1+r_{t-1}\right)-1 \leq 50 \%$. Further, we also set a daily return to missing if it is greater than $200 \%$. This cleaning of daily returns is done as it is important for calculating one of the illiquidity measures: the price impact. For the monthly returns following Griffin et al (2010), we set those monthly return to be zero if $r_{t-1}>300 \%$ or $r_{t}>300 \%$ and $\left(1+r_{t}\right) *\left(1+r_{t-1}\right)-1 \leq 50 \%$. In addition to this we set all monthly returns that are greater than $800 \%$ to be missing ${ }^{5}$.

In addition to these cleaning procedures, we have also opted to remove all those stocks which in their previous month have prices lower than $\$ A U$ 0.1. As noted in footnote 3 of Ince and Porter (2006), the impact of implausible observations can be reduced by using alternative price screens like $1,0.25$ and 0.1 . We find this observation very relevant for the Australian stock market. For example, even after applying various cleaning procedure the stocks with prices lower than $\$ A U$ 0.1, have average monthly returns of $5.08 \%$. Further, the monthly price impact of these stocks, (which traces an impact of one $\$ A U$ traded volume on returns) is 0.82 on average. Indeed, there are stocks which have a monthly ratio over

\footnotetext{
${ }^{4}$ Amihud et al. (2015) reported the number of firms for the Australian markets is 2,699 from January, 1990 to December, 2011. Slightly higher number of firms in our sample is due to longer coverage of data sample.

${ }^{5}$ Griffin et al. (2010) cleaning procedures are defined for weekly returns, therefore to make them applicable for monthly returns we adjust the cut-offs.
} 
1000. In light of this, we can safely say that the stocks retain for the analysis for our study are void of extreme observations. As a comparison, the price impact measure provided in Amihud et al. (2015) for the Australian market is 0.090 and in our study the same is 0.052 . After using these filters, the average number of firms in our study is 890, as compared in (Amihud et al., 2015).

\section{Illiquidity Measure}

To test the pricing implications of illiquidity risk, two different proxy measures of illiquidity are selected. First, we use the price impact measure as proposed by Amihud (2002), which has been used by a number of studies. Second measure is the zero-return measure as proposed by Lesmond et al. (1999) and used by Bekaert, Harvey, and Lundblad (2007); Lee (2011) in the global context.

Amihud (2002) proposes a measure of illiquidity which captures the impact of trading volume upon the absolute return of a stock. Stocks that are illiquid respond more to the trading volume in comparison with liquid stocks due to the information asymmetry, which is much higher for illiquid stocks. Numerous studies (Amihud, 2002; Amihud et al., 2015; Acharya \& Pedersen, 2005; Hou, Karolyi, \& Kho, 2011) use this measure to estimate stock illiquidity. For the daily return of a stock on given day, $r_{i, d}$, with the daily trading in Australian dollar, $\left(\right.$ volume $\left._{i, d}\right)$ the price impact is a ratio $\frac{r_{i, d}}{\text { volume }_{i, d}}$, which is averaged across the number of days for which stock is traded in a month.

Mathematically:

$$
P I_{i, t}=\left(1 / N_{i, t} \sum_{d}\left|r_{i, d}\right| / \text { volume }_{i, d}\right.
$$

Where, $N_{i, t}$, is number of days in a month for which the stock is traded. The price impact, $P_{i, t}$, measure is then averaged within each month for each stock and for the overall Australian stock market. In the seminal paper by Amihud (2002), there are a number of restrictions imposed on $P I^{\prime} s$ calculation. One of them is that a stock is traded for at least 15 days in a month. However, this restriction is relaxed in recent studies (for instance in Amihud et al. (2015)). The obvious reason for relaxing this restriction is that by only accounting for stocks that are traded for 15 days leads to the removal of most illiquid stocks from the sample.

One of the simplest illiquidity measures is proposed by (Lesmond et al., 1999). That is, the number of zero returns for a stock in a given month. If these zero returns are higher for a given stock, then it implies illiquidity for that stock is higher. The intuition is simple, for instance, if a stock is not traded for any given day when absolute return for the overall market is not zero, implies that the transaction cost for trading that stock is higher than the profit one would earn by trading it; therefore, a rational investor would abstain from trading the stock on that day. Thus, we would find zero-return for that stock. Consequently, the higher is the number of zero returns, the more illiquid is the stock. This measure can be calculated as

$$
\text { Zero-returns }=Z R D_{i, t} / T D_{i, t}
$$


Where, $Z R D_{i, t}$, shows number of zero return days in a month for a stock and, $T D_{i, t}$, shows the number of trading days in a month. This simple ratio gives the zero return measure, which is estimated for each stock and for the whole Australian stock market.

\section{Portfolio Construction}

To find the effect of illiquidity, we form portfolios on the basis of two different illiquidity measures. Using each measure of illiquidity we form ten portfolios. We use a monthly sorting procedure for the construction of portfolios ${ }^{6}$. That is for, each month, illiquidity of a stock is estimated through price impact and zero-returns. The stocks are split into ten deciles, based on their previous month's illiquidity. Portfolio P-1 (decile 1) is composed of the stocks that are the most liquid 10 percent stocks in our sample. By comparison, the most illiquid portfolio P-10 (decile 10) contains stocks which are the most illiquid.

Table 1 shows the average illiquidities and average returns for the ten decile portfolios which are sorted on the basis of previous months of illiquidity. As can be seen, each portfolio is increasing in the respective measure of illiquidity. Furthermore, there is a quite sizable economic premium related to illiquidity, particularly through price impact. For instance, in Table 1, Panel A, the yearly premium for the most illiquid portfolio P-10 over $\mathrm{P}-1$ is $17.96 \%$, when illiquidity is measured by price impact. However, the return dispersion is not that sizable when zero-return as a measure of illiquidity is used, as it is only $7.33 \%$ per annum as shown in Table 1 Panel B. This indicates that the zero-return produced the minimum illiquidity premium. However, we note that the sorting procedure with zero-returns is advantageous for the most illiquid portfolio as number of average firms is quite lower for the most illiquid portfolios ${ }^{7}$. Generally the average numbers of firms are quite similar for each portfolio when the same are sorted with price impact.

Two different measures of monthly Illiquidity are calculated for each stock using equation (7) and (8) for the period of 1988-2014. In Panel A, the price impact measure which gauges an impact of one AUS $\$$ traded volume upon absolute returns is shown for each portfolio. Returns show the average of monthly return (equally weighted) for the stocks falling in each portfolio. Firms show the average number of firms falling in each portfolio. The panel B presents the same information with zero returns, where zero returns is the number of zero returns for any given stock within any month.

\footnotetext{
${ }^{6}$ As described in footnote 21 of Sadka (2005), that the factor loadings which we estimate for each portfolio using the whole sample period using equation (3),(4),(5) and (6) for whole sample are fixed, they are yet conditional at firms level due to monthly sorting procedure.

${ }^{7}$ The number of firms is un-equal with zero-returns in some deciles, as many firms have same number of monthly zero returns, therefore the sorting procedure allocate unequal number of stocks to different portfolios.
} 
Table 1

Construction of Portfolios

\begin{tabular}{lcccccc}
\hline \multirow{2}{*}{ Portfolio } & \multicolumn{3}{c}{ Panel A } & \multicolumn{3}{c}{ Panel B } \\
& Price Impact & Returns & Firms & Zero-Returns & Returns & Firms \\
\hline P-1 & 0.004 & 0.957 & 80 & 15.136 & 0.672 & 111 \\
P-2 & 0.052 & 0.813 & 79 & 23.780 & 0.703 & 74 \\
P-3 & 0.150 & 0.802 & 79 & 30.730 & 0.590 & 80 \\
P-4 & 0.344 & 0.794 & 79 & 37.607 & 0.810 & 78 \\
P-5 & 0.751 & 0.931 & 79 & 44.026 & 0.843 & 75 \\
P-6 & 1.333 & 0.788 & 78 & 50.547 & 1.051 & 77 \\
P-7 & 2.674 & 0.777 & 78 & 57.505 & 1.263 & 74 \\
P-8 & 4.113 & 0.774 & 77 & 65.595 & 1.282 & 77 \\
P-9 & 8.106 & 0.685 & 76 & 74.577 & 1.319 & 74 \\
P-10 & 26.10 & 2.453 & 75 & 82.966 & 1.283 & 62 \\
\hline Authors' estimation & & & & &
\end{tabular}

\section{Estimation Procedure}

Previous studies that relate illiquidity effects to asset returns use innovations in the illiquidity series. Sadka (2006) suggests using innovation (surprises) in illiquidity instead of the level of illiquidity series. We follow (Sadka, 2006; Lee, 2011) and trace out innovations from the fitted $A R(2)$ models for twenty two illiquidity series, whereas the twenty illiquidity series are of the twenty portfolios which are constructed in the previous section. Lastly the remaining two series are representing market-wide illiquidity. The following $A R(2)$ model is estimated

$$
L_{t}^{i}=c+\sum_{i=1}^{2} \Psi_{i} L_{t-i}^{i}+\epsilon_{t}^{i}
$$

Where, $L_{t}^{i}$, represents the respective illiquidity series, $\Psi_{i}$, is the coefficients on the lag $i$. More importantly: $\epsilon_{t}^{i}$ is the innovation in the illiquidity series. Figure 1 gives a graphical illustration of the market-wide innovation in the illiquidity series for the two different measures of illiquidity.

\section{Empirical Results}

\section{Illiquidity Sorted Portfolios for the Australian Stock Market}

We estimate four betas using equations (3), (4), (5) and (6) using monthly portfolio returns, innovation in portfolios illiquidity, market returns, and innovation in market illiquidity. In Tables 2 Panel A and B we report four betas estimated for each portfolio based on the price impact and zero-return illiquidity measures. As can be seen, the first two illiquidity related betas for price impact portfolios, representing the risk with commonality in illiquidity, $\beta_{L 1}$, and representing the risk with wealth effect, $\beta_{L 3}$, are well in line with the expected illiquidity of these portfolios. However, the illiquidity related beta, $\beta_{L 2}$ (representing the flight to liquidity effect) is not monotonic for the most illiquid portfolios in relation as the others. 


\section{Figure 1}

Graphs shows monthly innovation in market-wide illiquidity series estimated through price impact and zero-return illiquidity measure.

\section{Price Impact}
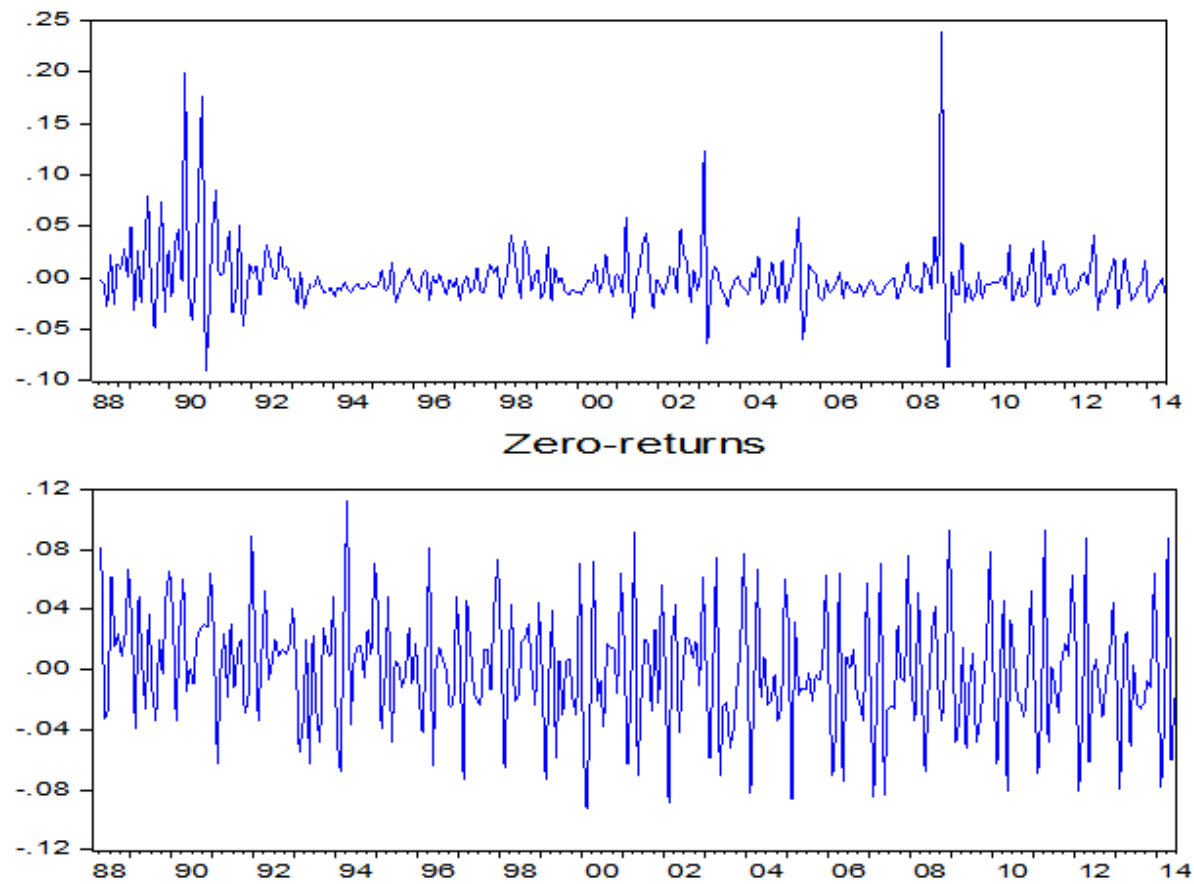

Table 2 provides different characteristics for ten equally weighted portfolios sorted on the basis of two different measures of illiquidity. The expected Illiquidity, shown as $E\left(C_{i}\right)$ is calculated as monthly averages of price impact and zero measure for each portfolio. The market beta $\beta_{m}$ and three illiquidity related betas $\beta_{L 1}, \beta_{L 2}$ and $\beta_{L 3}$ are estimated using equation (3), (4),(5) and (6). The illiquidity related characteristics are measured using all two measures of illiquidity and results shown as Panel A and B for the Australian stock market using the whole sample of 1988-2014.

Table 2 Panel B, reports variations in the market beta, and three illiquidity related betas for ten portfolios sorted on the zero-return illiquidity measure. A portfolio's zeroreturns increase in conjunction with the previous month's zero returns. However, illiquidity related betas do not take the expected patterns that we observe in Tables 2 Panel A. For example, the most illiquid portfolio (P-10) does not have the highest, $\beta_{L 1}$, nor the highest, $\beta_{L 3}$. However, there is some monotonicity with, $\beta_{L 2}$ which does not line up either with the expected illiquidity or with the realized returns of the portfolios. One can safely say that when Illiquidity in the Australian stock market is estimated through the zero-returns 
measure, we do not see the expected results.

Table 2

Variation in betas with two different illiquidity measures

\begin{tabular}{llllll}
\hline Portfolio & $E\left(C_{i}\right)$ & $\beta_{m}$ & $\beta_{L 1}$ & $\beta_{L 2}$ & $\beta_{L 3}$ \\
\hline P-1 & 0.00004 & 0.35263 & 0.00008 & -0.01574 & 0.00002 \\
P-2 & 0.00052 & 0.56827 & 0.00115 & -0.03995 & -0.00134 \\
P-3 & 0.00150 & 0.64919 & 0.00084 & -0.06573 & -0.00186 \\
P-4 & 0.00344 & 0.69675 & 0.00519 & -0.06374 & -0.00792 \\
P-5 & 0.00751 & 0.64002 & 0.00987 & -0.0656 & -0.01115 \\
P-6 & 0.01333 & 0.67485 & 0.02100 & -0.0876 & -0.02337 \\
P-7 & 0.02674 & 0.68061 & 0.20440 & -0.07921 & -0.07741 \\
P-8 & 0.04113 & 0.72264 & 0.05559 & -0.11151 & -0.05942 \\
P-9 & 0.08106 & 0.76041 & 0.14522 & -0.12751 & -0.03676 \\
P-10 & 0.26108 & 0.74924 & 0.59401 & -0.11305 & -0.44764 \\
\hline \multicolumn{5}{c}{ Panel B: Zero-returns } \\
Portfolio & $E\left(C_{i}\right)$ & $\beta_{m}$ & $\beta_{L 1}$ & $\beta_{L 2}$ & \\
\hline P-1 & 0.15136 & 0.49836 & 0.34633 & -0.01736 & -0.00557 \\
P-2 & 0.23780 & 0.58704 & 0.35961 & -0.04963 & -0.01487 \\
P-3 & 0.30730 & 0.64215 & 0.38114 & -0.04831 & -0.03541 \\
P-4 & 0.37607 & 0.67146 & 0.37386 & -0.07047 & -0.04863 \\
P-5 & 0.44026 & 0.66211 & 0.36160 & -0.06804 & -0.10504 \\
P-6 & 0.50547 & 0.68869 & 0.37118 & -0.07844 & -0.11836 \\
P-7 & 0.57505 & 0.63161 & 0.34248 & -0.08450 & -0.09536 \\
P-8 & 0.65595 & 0.58769 & 0.29888 & -0.05966 & -0.09728 \\
P-9 & 0.74577 & 0.50581 & 0.22052 & -0.05068 & -0.08160 \\
P-10 & 0.82966 & 0.36519 & 0.13699 & -0.07396 & -0.04018 \\
\hline Authors' estimation & & & &
\end{tabular}

\section{Empirical Results from Cross-section Regressions}

We estimate the following testable form of LCAPM model, equation (2), for twenty equally weighted portfolios for the Australian stock market for the period for 1988-2014.

$$
E\left(R_{i}\right)=\alpha+\psi_{i} E\left(C_{i}\right)+\lambda_{m} \beta_{m, i}+\lambda_{L 1} \beta_{L 1, i}-\lambda_{L 2} \beta_{L 2, i}-\lambda_{L 3} \beta_{L 3, i}
$$

Of these twenty portfolios, each set of ten portfolios are sorted using two different measures of illiquidity. Further, for all of these twenty portfolios, their level of illiquidity and illiquidity related betas are estimated using price impact and zero-returns separately. This type of testing has two advantages, first it increases the cross-sectional observations, second in addition of giving each measure of illiquidity an equal chance to price these twenty portfolios, it alludes which between these two measures is better ${ }^{8}$.

The above model is a slight variant of original LCAPM model proposed by Acharya and Pedersen (2005), as we estimate separately the each price of risk associated with the model related risk factors. This sort of testing is necessary owing to the high degree of correlation among the risk factors ${ }^{9}$. Therefore we estimate the above model, equation (10), separately for each factor, and it is conjectured that the factor that has the most

\footnotetext{
${ }^{8}$ The results provided for twenty portfolio are also consistent for ten portfolios when each measure of illiquidity is used to price the return structure of the portfolios sorted by them, these results can be furnished upon request.

${ }^{9}$ These correlation structure among model constituent variables can be provided upon request.
} 
significant pricing capacity, should reveal through its respective price of risk $(\lambda)$ associated with the factor, and through the regression's $R^{2}$. Table 3 provides results for the LCAPM model for individual factor models. We thus fit five versions of equation (10): M1 with the expected illiquidity level, M2 with the market risk, M3 with the commonality in illiquidity risk, M4 with the flight to liquidity risk and M5 with the depressed wealth risk.

In Table 3 Panel A, with price impact in M1, the expected illiquidity $E\left(C^{i}\right)$ is related positively and statistically significant, the coefficient is 0.0525 with a t-stat of 7.50 and associated adjusted $R^{2}$ is $74.40 \%$. This result shows that level of illiquidity is positively compensated as expected. M2 alludes to the pricing implication of market risk. The price of risk is negative with the insignificant t-stat value of -0.02, and with the lowest adjusted $R^{2}$ value $(-5.60 \%)$. This indicates the failure of CAPM to price the portfolios which are linked with illiquidity. M3 estimates the price of risk associated with commonality in illiquidity effect. The risk premium associated with this illiquidity related beta is 0.0228 with t-stat of 7.54 and adjusted $R^{2}$ of $74.60 \%$. The commonality in illiquidity is also positively compensated as expected.

\begin{tabular}{|c|c|c|c|c|c|c|c|}
\hline \multicolumn{8}{|c|}{ Panel A: Price impact } \\
\hline & Constant & $E(C i)$ & $\beta_{m}$ & $\beta_{L 1}$ & $\beta_{L 2}$ & $\beta_{L 3}$ & $R_{2}$ \\
\hline M1 & $\begin{array}{l}0.0074 \\
(13.14)\end{array}$ & $\begin{array}{c}0.0525 \\
(7.50)\end{array}$ & & & & & $\begin{array}{c}0.757 \\
(0.744)\end{array}$ \\
\hline M2 & $\begin{array}{c}0.0099 \\
(1.74)\end{array}$ & & $\begin{array}{c}(0.0001) \\
(0.02)\end{array}$ & & & & $\begin{array}{c}0.000 \\
(0.056)\end{array}$ \\
\hline M3 & $\begin{array}{l}0.0074 \\
(12.99)\end{array}$ & & & $\begin{array}{c}0.0228 \\
(7.54)\end{array}$ & & & $\begin{array}{c}0.760 \\
(0.746)\end{array}$ \\
\hline M4 & $\begin{array}{l}0.0061 \\
(2.190)\end{array}$ & & & & $\begin{array}{c}(0.0484) \\
(1.42)\end{array}$ & & $\begin{array}{c}0.100 \\
(0.050)\end{array}$ \\
\hline M5 & $\begin{array}{l}0.0075 \\
(16.11)\end{array}$ & & & & & $\begin{array}{c}(0.0336) \\
(9.40)\end{array}$ & $\begin{array}{c}0.831 \\
(0.821)\end{array}$ \\
\hline \multicolumn{8}{|c|}{ Panel B: Zero-returns } \\
\hline M1 & $\begin{array}{l}0.0043 \\
(2.170)\end{array}$ & $\begin{array}{c}0.0116 \\
(2.97)\end{array}$ & & & & & $\begin{array}{l}0.329 \\
0.292\end{array}$ \\
\hline M2 & $\begin{array}{l}0.0099 \\
(1.740)\end{array}$ & & $\begin{array}{c}(0.0001) \\
(0.02)\end{array}$ & & & & $\begin{array}{c}0.000 \\
(0.056)\end{array}$ \\
\hline M3 & $\begin{array}{l}0.0221 \\
(6.310)\end{array}$ & & & $\begin{array}{c}(0.0385) \\
(3.59)\end{array}$ & & & $\begin{array}{c}0.418 \\
(0.385)\end{array}$ \\
\hline M4 & $\begin{array}{l}0.0069 \\
(3.030)\end{array}$ & & & & $\begin{array}{c}-0.0485 \\
(1.37)\end{array}$ & & $\begin{array}{r}0.095 \\
(0.045)\end{array}$ \\
\hline M5 & $\begin{array}{l}0.0093 \\
(5.590)\end{array}$ & & & & & $\begin{array}{c}(0.0076) \\
(0.35)\end{array}$ & $\begin{array}{r}0.007 \\
(0.048)\end{array}$ \\
\hline
\end{tabular}

Table 3 presents the estimation results for the LCAPM model, equation (10), for the twenty equally weighted portfolios for the Australian stock market for the period of 19882014, the illiquidity is estimated in two different ways and their results are shown in Panel A, B and C. M1 is expected illiquidity shown as $E(\mathrm{Ci}), \mathrm{M} 2$ is a simple CAPM, and M3, M4 and M5 are estimated, $\beta_{L 1}, \beta_{L 2}, \beta_{L 3}$, respectively. Whereas, M6 specification includes all beta risks. The $R_{2}$ and adjusted $R_{2}$ are shown in parenthesis the last columns. Similarly, for each coefficient associated t-stats are provided in parenthesis. 
M4 (when $\beta_{L 2, i}$ is used as illiquidity related risk) has the expected sign on the price of risk. Although, it is marginally significant; but, it has the lowest adjusted $R^{2}$ among all illiquidity related risks specifications. It is pertinent to mention that many studies initially Amihud (2002); Pástor and Stambaugh (2003) among others) have only used this illiquidity related risk. The results from M4 suggest that using a single illiquidity risk factor would lead us to conclude that illiquidity risk is not that significantly priced.

Lastly, M5 uses $\beta_{L 3, i}$ as illiquidity related beta, which accounts for the risk of increase in a stock's illiquidity in relation with market returns. As expected we find that the price of risk for $\beta_{L 3, i}$ is negative: -0.0336 , with a t-stat of -9.40 , and the highest adjusted $R^{2}$ of $82.10 \%$ among all five models. In order to understand the economic significance of $\beta_{L 3, i}$, we estimate its predicted premium using the associated price of risk in model (10) as follows,

$$
\lambda_{L 3}\left(\beta_{L 3, p-10}-\beta_{L 3, p-1}\right)
$$

Where P-10 is the most illiquid portfolio and P-1 is the most liquid portfolio. These exposures are provided in Table 2 for the price impact. The illiquidity related betas are -0.4476 and 0.0001 for these portfolios and the price of risk associated with this beta is -0.0336. Using the above relationship, gives $18.05 \%$ factor premium annually, whereas the realized premium is $17.96 \%$ for the price impact related portfolios (Table 1). In fact the LCAM predicts almost $100 \%$ illiquidity premium for the Australian markets. This result enunciate that the price impact measure not only gives the higher premium but also contributes to the success of the model.

On the other hand when LCAPM model is tested using the zero-returns measure the results are not that striking. These results are reported in Table 3 Panel B. It become obvious by looking into adjusted $R^{2}$ of all illiquidity related models of M1, M3, M4 and M5, are not that suceesful in comparisonts to the results reported by price impact measure. The coefficient on the level of illiquidity is the only significant with an accurate sign. Although the risk of commonality in illiquidity in M3 is also significantly priced, but the sign is counter intuitive, as we do not expect that stocks that become illiquid when the overall stock market becomes illiquid will provide any hedging advantage. The most important result is that the price of risk associated with $\beta_{L 3, i}$ in M5 is statistically insignificant. Infact the adjusted $R^{2}$ is negative $-4.80 \%$. Unsurprisingly, there is no premium for bearing $\beta_{L 3, i}$ illiquidity risk. Nevertheless, with zero-returns the results of none pricing of illiquidity risks are in line with Lee (2011) for the developed stock markets in which the Australian stock market is included.

\section{Conclusion}

This study discusses two aspects of illiquidity related literature. The magnitude of illiquidity premium for any market, its relationship with chosen measure of illiquidity and the likely strategy to find the maximum illiquidity premium. We show that both of these questions are linked with the choice of illiquidity measure by taking Australian stock market as a test case. Once we use two different measures of illiquidity we find that the magnitude of illiquidity is subject to variation even within country analysis, with price impact it is 
the highest and with zero-return the lowest. Further it is not necessary that price impact measure consistently give high premium for other markets. As a case in point for Finland, the illiquidity premium with zero return is higher than with price impact. Therefore, it will not be a surprise that multiple illiquidity premiums may surface for different markets. The main reason for such results is that on ex ante basis no researcher can determine which measure of illiquidity may yield the maximum premium. On the other hand, this study suggests that evidence of pricing of illiquidity risk and success of any such measure in bringing the higher spread between the returns of the most illiquid and liquid stocks is interlinked. Therefore, if the quest of finding maximum illiquidity premium is the main purport of illiquidity related literature. Then the best strategy of such studies is to use all measures of illiquidity so, far suggested in the literature to analyze with which the maximum illiquidity premium is associated within the context of each country. Therefore, this study can be extended for the global markets in pursuit of finding the maximum illiquidity premium. 


\section{References}

Acharya, V. V., \& Pedersen, L. H. (2005). Asset pricing with liquidity risk. Journal of Financial Economics, $77(2), 375-410$.

Amihud, Y. (2002). Illiquidity and stock returns: Cross-section and time-series effects. Journal of Financial Markets, 5(1), 31-56.

Amihud, Y., Hameed, A., Kang, W., \& Zhang, H. (2015). The illiquidity premium: International evidence. Journal of Financial Economics, 117(2), 350-368.

Amihud, Y., Mendelson, H., Pedersen, L. H., et al. (2005). Liquidity and asset prices. Foundations and Trends in Finance, 1(4), 269-364.

Bekaert, G., Harvey, C. R., \& Lundblad, C. (2007). Liquidity and expected returns: Lessons from emerging markets. The Review of Financial Studies, 20(6), 1783-1831.

Black, F. (1972). Capital market equilibrium with restricted borrowing. The Journal of Business, 45(3), 444-455.

Butt, H. A., \& Virk, N. S. (2015). Liquidity and asset prices: An empirical investigation of the nordic stock markets. European Financial Management, 21 (4), 672-705.

Chordia, T., Roll, R., \& Subrahmanyam, A. (2002). Order imbalance, liquidity, and market returns. Journal of Financial Economics, 65(1), 111-130.

Corwin, S. A., \& Schultz, P. (2012). A simple way to estimate bid-ask spreads from daily high and low prices. The Journal of Finance, 67(2), 719-760.

Fong, K. Y., Holden, C. W., \& Trzcinka, C. A. (2017). What are the best liquidity proxies for global research? Working paper, Indiana University.

Griffin, J. M., Kelly, P. J., \& Nardari, F. (2010). Do market efficiency measures yield correct inferences? A comparison of developed and emerging markets. The Review of Financial Studies, 23(8), 3225-3277.

Hou, K., Karolyi, G. A., \& Kho, B.-C. (2011). What factors drive global stock returns? The Review of Financial Studies, 24 (8), 2527-2574.

Ince, O. S., \& Porter, R. B. (2006). Individual equity return data from Thomson Datastream: Handle with care! Journal of Financial Research, 29(4), 463-479.

Lee, K.-H. (2011). The world price of liquidity risk. Journal of Financial Economics, $99(1), 136-161$.

Lesmond, D. A., Ogden, J. P., \& Trzcinka, C. A. (1999). A new estimate of transaction costs. The Review of Financial Studies, 12(5), 1113-1141.

Lintner, J. (1965). The valuation of risk assets and the selection of risky investments in stock portfolios and capital budgets. The Review of Economics and Statistics, $47(1)$, $13-37$.

Mossin, J. (1966). Equilibrium in a capital asset market. Econometrica: Journal of the Econometric Society, 34(4), 768-783.

Pástor, L., \& Stambaugh, R. F. (2003). Liquidity risk and expected stock returns. Journal of Political Economy, $111(3), 642-685$.

Raza, S. A., \& Karim, M. Z. A. (2016). Do liquidity and financial leverage constrain the impact of firm size and dividend payouts on share price in emerging economy. Journal of Finance and Economics Research, 1(2), 73-88. 
Roll, R. (1984). A simple implicit measure of the effective bid-ask spread in an efficient market. The Journal of Finance, 39(4), 1127-1139.

Sadka, R. (2006). Momentum and post-earnings-announcement drift anomalies: The role of liquidity risk. Journal of Financial Economics, 80(2), 309-349.

Sharpe, W. F. (1964). Capital asset prices: A theory of market equilibrium under conditions of risk. The Journal of Finance, 19(3), 425-442. 